\title{
Meta-analysis of the association of the CYP2J2 G-50T polymorphism with coronary artery disease
}

\author{
Jian Chen ${ }^{1}$, Dong-Fei Wang1, Guo-Dong Fu², Jie Ding ${ }^{1}$, Lei-Yang Chen ${ }^{2}$, Jia-Lan Lv', \\ Juan Fang ${ }^{1}$, Xiang Yin ${ }^{1}$ and Xiao-Gang Guo ${ }^{1,2}$ \\ ${ }^{1}$ Department of Cardiology, The First Affiliated Hospital, School of Medicine, Zhejiang University, Hangzhou 310003, China \\ ${ }^{2}$ Pujiang Branch of the First Affiliated Hospital, School of Medicine, Zhejiang University, Cardiavascular Center of Middle \\ Zhejiang, Jinhua 322200, China
}

Correspondence to: Xiao-Gang Guo, email: gxg22222@zju.edu.cn

Keywords: CYP2J2, G-50T polymorphism, CAD, meta-analysis

Received: May 07, $2017 \quad$ Accepted: July 12, $2017 \quad$ Published: July 24, 2017

Copyright: Chen et al. This is an open-access article distributed under the terms of the Creative Commons Attribution License 3.0 (CC BY 3.0), which permits unrestricted use, distribution, and reproduction in any medium, provided the original author and source are credited.

\section{ABSTRACT}

The association of the CYP2J2 G-50T polymorphism with coronary artery disease has been explored, but the results remain controversial. Thus, a meta-analysis was conducted to provide a comprehensive estimate of this association. We selected ten articles encompassing 12 independent case-control studies with 7063 cases and 10,453 controls for this meta-analysis. Overall, we found significant associations between the CYP2J2 G-50T polymorphism and coronary artery disease risk in three genetic models (allele model: odds ratio $(O R)=1.19,95 \%$ confidence interval $(C I)=1.05-1.34$; homozygote model: $\mathrm{OR}=2.25,95 \% \mathrm{CI}=1.27-4.01$; recessive model: $O R=2.17,95 \% C I=1.22-3.86)$. In these three genetic models, a significant association was observed in Caucasians but not in Asians when the data were stratified by ethnicity. However, no significant associations were found between the CYP2J2 polymorphism G-50T and coronary artery disease risk in heterozygote model and dominant model. In conclusion, our meta-analysis suggested that the CYP2J2 G-50T polymorphism was associated with coronary artery disease risk in the allele, homozygote and recessive models in Caucasians.

\section{INTRODUCTION}

Coronary artery disease (CAD) is a major cause of cardiovascular morbidity and mortality worldwide [1]. However, we do not totally understand its fundamental mechanism. As a multifaceted and polygenic illness, CAD may result from interactions between various environmental influences and genetic factors [2, 3]. Epidemiological studies have demonstrated that CAD is the consequence of several risk factors, such as age, body mass index (BMI), smoking, less exercise, gender, diabetes, hypercholesterolemia and low intake of dietary fiber. In addition to these risks, it is undeniable that hereditary factors play a crucial role. Until now, both genome-wide association studies (GWASs) and candidate gene studies have stated that numerous genetic variants are associated with susceptibility to CAD in various populations $[4,5]$.
Cytochrome P450 (CYP) enzyme 2J2 (CYP2J2) is one of the predominant CYP epoxygenase isoforms and is abundantly expressed in heart tissue [6]. In endothelial cells and cardiomyocytes, epoxyeicosatrienoic acids (EETs) are predominantly synthesized by CYP2J2 [7], which has been considered a vascular protective factor $[8,9]$. In CYP2J2, the G-50T (CYP2J2-76G > T; *7 allele) polymorphism in the proximal promoter disturbs a Sp1transcription factor binding site and brings about less CYP2J2 transcription [10]. Some previous researches have reported that the $C Y P 2 J 2-50 \mathrm{~T}$ variant allele was associated with CAD risk $[10,11]$, but there are a few opposing published results [12-19]. In addition, a metaanalysis has been conducted to assess the relationship between the CYP2J2-50T polymorphism and CAD risk and had a negative result, which was not analyzed in detail [13]. Against this background, we add some new studies in our meta-analysis and present a more comprehensive 
analysis to evaluate the association between the CYP2J250T polymorphism and CAD risk.

\section{RESULTS}

\section{Study characteristics}

The process of study selection is shown in Figure 1. In total, there were 419 potentially relevant publications found through the literature search. Then, we screened the titles, abstracts and full-texts and excluded 409 articles due to unrelated research, review and data duplication. Lastly, a total of ten studies, including 7063 cases and 10,453 controls, were included in this meta-analysis. Among these publications, only two studies contained different population research. In the controls of all included studies, genotype distributions were consistent with Hardy-Weinberg equilibrium (HWE). The detailed characteristics of each study are listed in Table 1, and Table 2 shows the genotype distributions of the CYP $2 J 2$ G-50T polymorphism in cases and controls.

\section{Results of the meta-analysis}

The main results of the meta-analysis are summarized in Table 3. The study by Lee et al. was excluded in the pooled analysis of all genetic models, except for the dominant model, because of the unknown rate of the mutational homozygote (TT) in case and control groups. Additionally, as a result of the absence of the mutational homozygote (TT) in both case and control groups, the study by Lung et al. was excluded in the homozygote genetic model and the recessive model. Overall, no significant association was found between the CYP2J2 G-50T polymorphism and CAD risk in two genetic models (heterozygote model, $\mathrm{OR}=1.13,95 \% \mathrm{CI}=0.99$ $1.28, P=0.071$; dominant model, OR $=1.09,95 \% \mathrm{CI}$ $=0.97-1.22, P=0.137)$. However, a different result was obtained in the next analysis. The risk was significantly altered for the CYP2J2 G-50T polymorphism and CAD in the remaining three comparisons ( $\mathrm{T}$ vs. $\mathrm{G}, \mathrm{OR}=1.19,95 \%$ $\mathrm{CI}=1.05-1.34, P<0.01$; TT vs. GG, $\mathrm{OR}=2.25,95 \% \mathrm{CI}=$ $1.27-4.01, P<0.01$; TT vs. GT $+\mathrm{GG}, \mathrm{OR}=2.17,95 \%$ $\mathrm{CI}=1.22-3.86, P<0.01)($ Figure 2$)$.

\section{Subgroup analysis results}

To investigate whether the association between CYP2J2 G-50T polymorphism and CAD varies among different populations, we performed subgroup analysis based on the region of origin of the study population. In the subgroup analyses of ethnicity, a significant association was observed in Caucasians under the above three genetic models ( $\mathrm{T}$ vs. $\mathrm{G}, \mathrm{OR}=1.27,95 \% \mathrm{CI}=1.06-1.51$, $I^{2}=38.1 \%$; TT vs. GG, OR $=2.80,95 \% \mathrm{CI}=1.18-6.68$, $I^{2}=0.0 \%$; TT vs. GT $+\mathrm{GG}, \mathrm{OR}=2.74,95 \% \mathrm{CI}=1.15-$

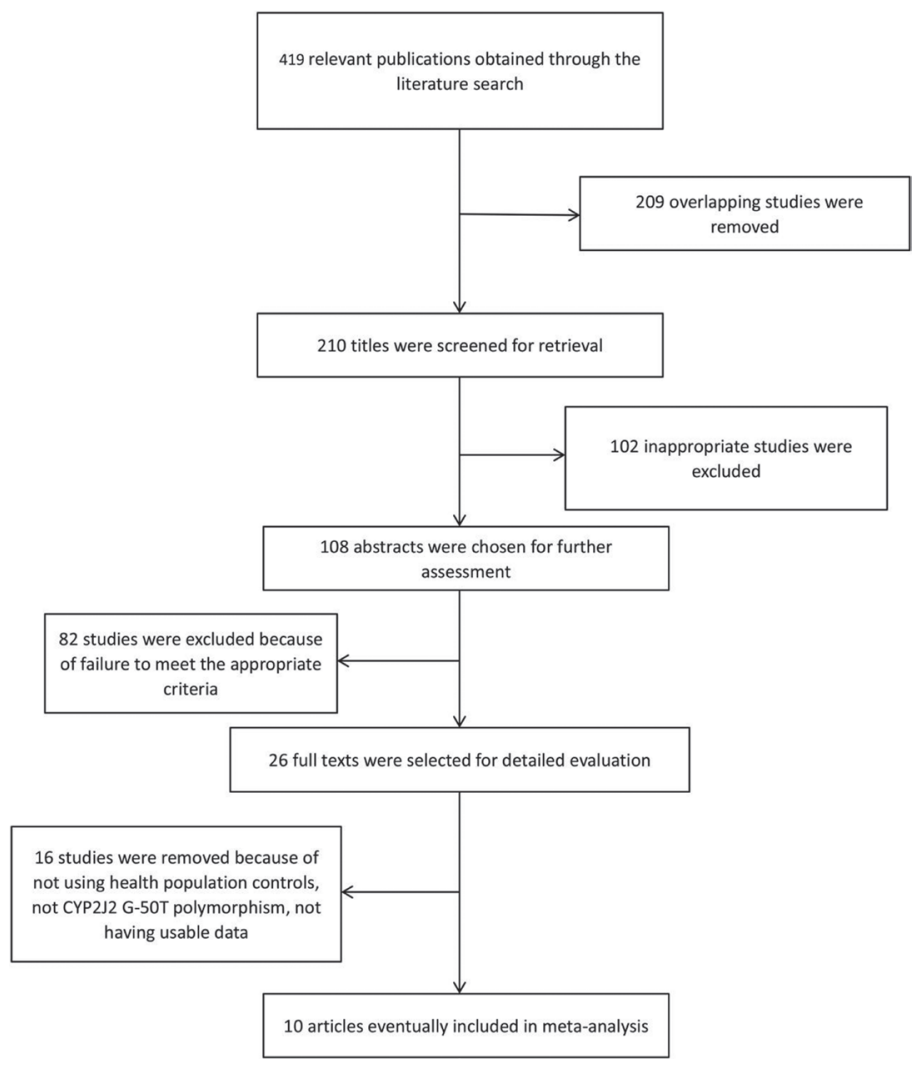

Figure 1: Flow diagram of studies through the meta-analysis. 
Table 1: Characteristics of the included studies

\begin{tabular}{|c|c|c|c|c|c|c|c|}
\hline $\begin{array}{l}\text { Included } \\
\text { study }\end{array}$ & Year & Ethnicity & $\begin{array}{c}\text { Genotyping } \\
\text { method }\end{array}$ & $\begin{array}{c}\text { Source of } \\
\text { controls }\end{array}$ & No. of case & No. of control & $\begin{array}{c}\text { Quality } \\
\text { score }\end{array}$ \\
\hline Arun Kumar et al. & 2015 & Asians & Real-time PCR & HB & 287 & 321 & 9 \\
\hline Tzveova et al. & 2015 & Caucasians & Taqman & PB & 254 & 470 & 10 \\
\hline Zhu et al. & 2013 & Asians & Taqman & PB & 573 & 455 & 11 \\
\hline Zhu et al. & 2013 & Asians & Taqman & PB & 286 & 138 & 11 \\
\hline Xu et al. & 2011 & Asians & Taqman & $\mathrm{HB}$ & 1344 & 1267 & 9 \\
\hline Fava et al. & 2010 & Caucasians & Taqman & $\mathrm{PB}$ & 132 & 5608 & 9 \\
\hline Lee et al. & 2007 & Caucasians & MALDI TOF MS & $\mathrm{PB}$ & 731 & 566 & 10 \\
\hline lee et al. & 2007 & $\begin{array}{l}\text { African- } \\
\text { American }\end{array}$ & MALDI TOF MS & PB & 211 & 268 & 10 \\
\hline Hoffmann et al. & 2007 & Caucasians & PCR & $\mathrm{PB}$ & 2547 & 696 & 11 \\
\hline Liu et al. & 2007 & Asians & PCR & $\mathrm{HB}$ & 200 & 200 & 9 \\
\hline Lung et al. & 2006 & Asians & PCR & HB & 209 & 209 & 9 \\
\hline Spiecker et al. & 2004 & Caucasians & PCR & HB & 289 & 255 & 10 \\
\hline
\end{tabular}

PB: Population-based; HB: Hospital-based; MALDI TOF MS: matrix-assisted laserdesorption/ionization time-of-flight mass spectrometry; PCR, polymerase chain reaction.

$6.53, I^{2}=0.0 \%$ ) (Figure 3). In contrast, we did not find any significant relationship between $C Y P 2 \mathrm{~J} 2 \mathrm{G}-50 \mathrm{~T}$ polymorphism and CAD in Asians (Figure 3).

\section{Test of heterogeneity}

According to $P$ values of the Chi-Square-based Q-statistical test, no significant heterogeneity was detected between studies in all genetic models (Table 3). Therefore, we used a fixed-effects model for pooled analysis in all genetic models.

\section{Sensitivity analysis and publication bias}

The stability of the overall results was also assessed by sequential omission of individual studies. Sensitivity analysis demonstrated the reliability and stability of our results because the combined results were not significantly influenced by any individual study. We used funnel plots to detect publication bias and the shape of the Begg 's funnel plot found no obvious asymmetry, which suggests the absence of publication bias in the overall meta-analysis (Figure 4). The results of Egger's test were as follows: (allele: $P=0.218$; homozygous: $P=0.632$; recessive: $P=0.635)$, which further provided no evidence of publication bias.

\section{DISCUSSION}

Like other CYP2 family genes, CYP2J2 contains nine exons and eight introns and spans $\sim 40.3 \mathrm{~kb}$ on human chromosome 1, band p31.3-p31.2 [20]. EETs, synthesized by CYP2J2, have many important physiological actions including maintaining cardiomyocyte viability suffering from damaging stimuli and enhance the recovery of cells from oxygen deprivation [21]. The G-50T (also called rs890293) polymorphism is one of the most relevant polymorphisms associated with $\mathrm{CAD}$ according to polymorphism frequency and functional importance [22]. Decreasing quantity of CYP2J2 protein may affect EETs generation and then subsequently increase the incidence of CAD. The study by Spiecker et al. has proven that the G-50T polymorphism can lead to less CYP2J2 gene transcription by disturbing a Sp1 transcription factor binding site [10]. Several studies have aimed at investigating the relationship between the CYP2J2 G-50T polymorphism and CAD risk and have found there is an association between them $[10,11]$. Conversely, other researches [12-19] also had comprehensive studies of the role of the CYP2J2 G-50T polymorphism in the development of CAD risk and found no significant association between the CYP2J2 G-50T polymorphism and CAD susceptibility, which indicates that the development of risk of CAD may not be affected by variant alleles.

Therefore, a meta-analysis containing 10 case-control studies with 7063 cases and 10,453 health controls was performed to comprehensively evaluate the effect. As far as we know, the result of a previous meta-analysis showed that there was no significant association between CYP2J2 G-50T polymorphism and CAD risk in dominant model comparisons $(\mathrm{OR}=1.12,95 \% \mathrm{CI}=0.95-1.31)$ and additive model comparisons $(\mathrm{OR}=1.15,95 \% \mathrm{CI}=0.97-1.36)$ [13]. However, the study carried out by $\mathrm{Xu}$ et al. did not offer any detailed data in the meta-analysis and did not comprehensively evaluate the association in all 
comparisons. Thus, we subsequently added some new eligible researches into our more complete meta-analysis to extensively investigate the role of the CYP2J2 G-50T polymorphism in the development of CAD. Our study suggested that CYP2J2 G-50T polymorphism was not associated with CAD risk under the dominant model and heterozygote model. However, there was a significant relationship between the $C Y P 2 J 2$ G-50T polymorphism and CAD risk in other genetic models ( $T$ vs. G, $\mathrm{OR}=1.19,95 \% \mathrm{CI}=1.05-1.34$; TT vs. $\mathrm{GG}, \mathrm{OR}=2.25$, $95 \% \mathrm{CI}=1.27-4.01$; $\mathrm{TT}$ vs. $\mathrm{GT}+\mathrm{GG}, \mathrm{OR}=2.17,95 \%$ $\mathrm{CI}=1.22-3.86)$. In addition, the stratification analyses of studies by ethnicity found that the CYP2J2 G-50T polymorphism in Caucasians was significantly associated

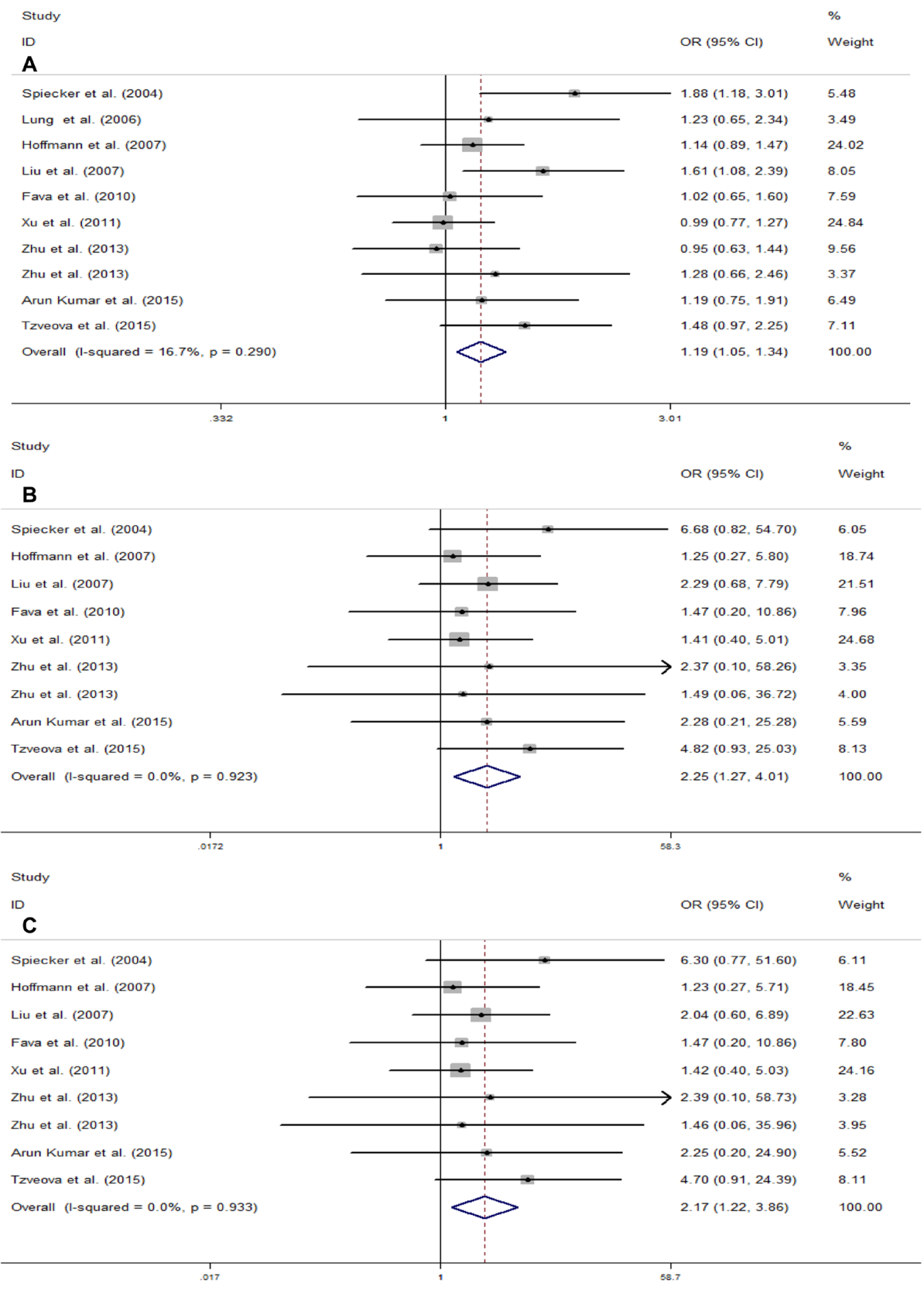

Figure 2: Meta-analysis for the association of CYP2J2 G-50T polymorphism and CAD risk in total population. (A) Allele genetic model (T vs.G); (B) Homozygote genetic model (TT vs. GG); (C) Recessive genetic model (TT vs. GT + GG). For each study, the estimation of OR and its $95 \% \mathrm{CI}$ are plotted with a box and a horizontal line. $\diamond$, pooled ORs and its $95 \%$ CIs. 
Table 2: The genotypes distribution and allele frequencies of eligible studies

\begin{tabular}{|c|c|c|c|c|c|c|c|c|}
\hline \multirow{2}{*}{$\begin{array}{l}\text { Included } \\
\text { study }\end{array}$} & \multirow{2}{*}{ Ethnicity } & \multirow{2}{*}{ group } & \multicolumn{3}{|c|}{ genotype } & \multicolumn{2}{|c|}{ Allele frequencies (\%) } & \multirow{2}{*}{ HWE $(P)$} \\
\hline & & & GG & GT & TT & $\mathbf{G}$ & $\mathbf{T}$ & \\
\hline \multirow{2}{*}{ Arun Kumar et al. } & \multirow{2}{*}{ Indian } & case & 251 & 34 & 2 & 93.4 & 6.6 & \multirow{2}{*}{0.99} \\
\hline & & control & 286 & 34 & 1 & 94.4 & 5.6 & \\
\hline \multirow{2}{*}{ Tzveova et al. } & \multirow{2}{*}{ Bulgarian } & case & 217 & 32 & 5 & 91.7 & 8.3 & \multirow{2}{*}{0.68} \\
\hline & & control & 428 & 50 & 2 & 94.3 & 5.7 & \\
\hline \multirow{2}{*}{ Zhu et al. } & \multirow{2}{*}{ Han } & case & 521 & 51 & 1 & 95.4 & 4.6 & \multirow{2}{*}{0.28} \\
\hline & & control & 411 & 44 & 0 & 95.2 & 4.8 & \\
\hline \multirow{2}{*}{ Zhu et al. } & \multirow{2}{*}{ Uygur } & case & 253 & 32 & 1 & 94.1 & 5.9 & \multirow{2}{*}{0.56} \\
\hline & & control & 125 & 13 & 0 & 95.3 & 4.7 & \\
\hline \multirow{2}{*}{$\mathrm{Xu}$ et al. } & \multirow{2}{*}{ China } & case & 1220 & 118 & 6 & 95.2 & 4.8 & \multirow{2}{*}{0.56} \\
\hline & & control & 1147 & 116 & 4 & 95.1 & 4.9 & \\
\hline \multirow{2}{*}{ Fava et al. } & \multirow{2}{*}{ Swedes } & case & 112 & 19 & 1 & 92.0 & 8.0 & \multirow{2}{*}{0.33} \\
\hline & & control & 4760 & 819 & 29 & 92.2 & 7.8 & \\
\hline \multirow{2}{*}{ Lee et al. } & \multirow{2}{*}{ Caucasian } & case & 648 & \multicolumn{2}{|c|}{83} & \multirow{2}{*}{93.6} & \multirow{2}{*}{6.4} & \multirow{2}{*}{$>0.05$} \\
\hline & & control & 501 & & & & & \\
\hline \multirow{2}{*}{ lee et al. } & \multirow{2}{*}{$\begin{array}{l}\text { African- } \\
\text { American }\end{array}$} & case & 167 & & & 8 & 155 & $>005$ \\
\hline & & control & 189 & & & 84.5 & 15.5 & $>0.05$ \\
\hline Uoffmonn 1 & Gonmon & case & 2225 & 313 & 9 & 93.5 & 6.5 & 002 \\
\hline Hormann et al. & Germany & control & 618 & 76 & 2 & 94.3 & 5.7 & 0.83 \\
\hline I in 1 & Chime & case & 136 & 56 & 8 & 82.0 & 18.0 & 0.15 \\
\hline Liu et al. & Cnina & control & 156 & 40 & 4 & 88.0 & 12.0 & 0.45 \\
\hline & & case & 187 & 22 & 0 & 94.7 & 5.3 & \\
\hline Lung et al. & China & control & 191 & 18 & 0 & 95.7 & 4.3 & 0.52 \\
\hline Cniolror at 1 & Gormonr & case & 239 & 43 & 7 & 90.1 & 9.9 & 78 \\
\hline spiecker et al. & Germany & control & 228 & 26 & 1 & 94.5 & 5.5 & 0.18 \\
\hline
\end{tabular}

$\mathrm{HWE}(P)$, the $P$-values of the Hardy-Weinberg equilibrium test of control group.

Table 3: The main results of this meta-analysis

\begin{tabular}{|c|c|c|c|c|c|c|c|c|c|c|}
\hline \multirow{3}{*}{$\begin{array}{c}\text { Genotype } \\
\text { contrast }\end{array}$} & \multirow{3}{*}{ population } & \multicolumn{2}{|c|}{ Sample size } & \multirow{3}{*}{$\begin{array}{l}\text { Type of } \\
\text { model }\end{array}$} & \multirow{3}{*}{$\begin{array}{c}\text { Number } \\
\text { of } \\
\text { studies }\end{array}$} & \multirow{2}{*}{\multicolumn{3}{|c|}{ Test of association }} & \multirow{2}{*}{\multicolumn{2}{|c|}{ Heterogeneity }} \\
\hline & & \multirow{2}{*}{ case } & \multirow{2}{*}{ control } & & & & & & & \\
\hline & & & & & & OR & $95 \% \mathrm{CI}$ & $P$ value & $I^{2}$ & $P$ value \\
\hline T vs. G & Over all & 6121 & 9619 & Fixed & 10 & $1.19^{*}$ & $1.05-1.34^{*}$ & $<0.01$ & $16.7 \%$ & 0.290 \\
\hline TT vs. GG & Over all & 5912 & 9410 & Fixed & 9 & $2.25^{*}$ & $1.27-4.01 *$ & $<0.01$ & $0.0 \%$ & 0.923 \\
\hline GT vs.GG & Over all & 6121 & 9619 & Fixed & 10 & 1.13 & $0.99-1.28$ & 0.071 & $0.0 \%$ & 0.661 \\
\hline $\begin{array}{c}\text { TT vs. } \\
\text { GT + GG }\end{array}$ & Over all & 5912 & 9410 & Fixed & 9 & $2.17 *$ & $1.22-3.86^{*}$ & $<0.01$ & $0.0 \%$ & 0.933 \\
\hline $\begin{array}{c}\mathrm{TT}+\mathrm{GT} \text { vs. } \\
\text { GG }\end{array}$ & Over all & 7063 & 10453 & Fixed & 12 & 1.09 & $0.97-1.22$ & 0.137 & $34.1 \%$ & 0.117 \\
\hline
\end{tabular}

OR: odds ratio; *OR with statistical significance.

with an increased risk for CAD in the three genetic models. Nevertheless, we did not found any association of the polymorphism with CAD risk in the Asian population, and these results suggest that the SNP may be an ethnicitydependent factor in CAD progression. Besides, the significant association only can be found under the allele 
model, recessive model and homozygote model, which suggested that the rare TT genotype may play a crucial role. To clarify inconsistence between our consequence and previous meta-analysis result, we performed a comparison and found a few reasons. First, previous study did not comprehensively evaluate the association in all comparisons and might ignore some association in a part of all genetic models. Second, we added new eligible researches and omitted unqualified articles when we perform a meta-analysis in some genetic models.

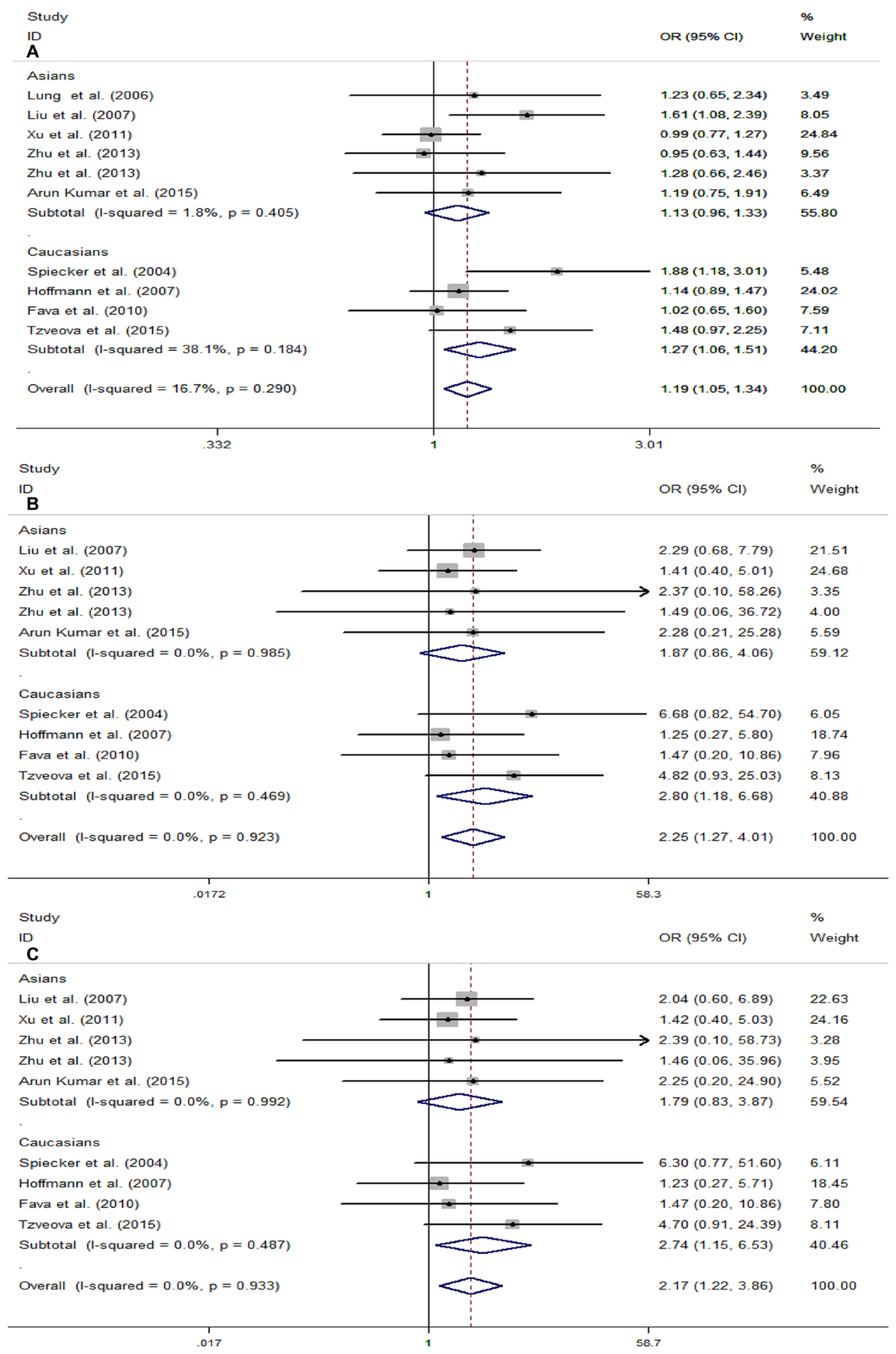

Figure 3: Forest plots for stratification study of the association between CYP2J2 G-50T polymorphism and CAD risk under the three genetic models. (A) T vs. G; (B) TT vs. GG; (C) TT vs.GG/GT. For each study, the estimation of OR and its 95\% CI are plotted with a box and a horizontal line. $\diamond$, pooled ORs and its $95 \%$ CIs. 
Some limitations of this meta-analysis should be addressed. Because no adjustment for other covariates was performed, our analyses based on unadjusted OR values may accordingly have low power when we estimated the real association. As the number of the included studies might be insufficient, some stratification analyses do not have enough statistical power to identify the effect. Environment factors may influence the association of the CYP2J2 G-50T polymorphism with CAD risk through a gene-environment interaction. However, we did not evaluate the potential geneenvironment effect in this study because of the unavailability of the original data.

In conclusion, our meta-analysis found that the CYP2J2 G-50T polymorphism among Caucasians was associated with CAD risk in certain genetic models, such as the allele model, recessive model and homozygote model. Thus, we can speculate that in Caucasians, the rare TT genotype may play an important role in the progression of CAD. However, more studies based on larger sample sizes are required to validate the present findings in the future.

\section{MATERIALS AND METHODS}

\section{Study identification}

Two authors independently conducted a systematic literature search of the PubMed, Elsevier, China National Knowledge Infrastructure platform and Wanfang databases to identify studies of the relationship between CYP2J2 G-50T polymorphism and CAD. To identify all possible studies as comprehensively as possible, we used the following various keywords: "CYP2J2", "polymorphism," "variant," "G-50T polymorphism," “-76G > T polymorphism”, "rs890293," "coronary artery disease," "CAD," "coronary heart disease," and "CHD." Additional studies were selected by searching references cited manually in the appropriate articles. The literature search was finally performed on April 25, 2017.
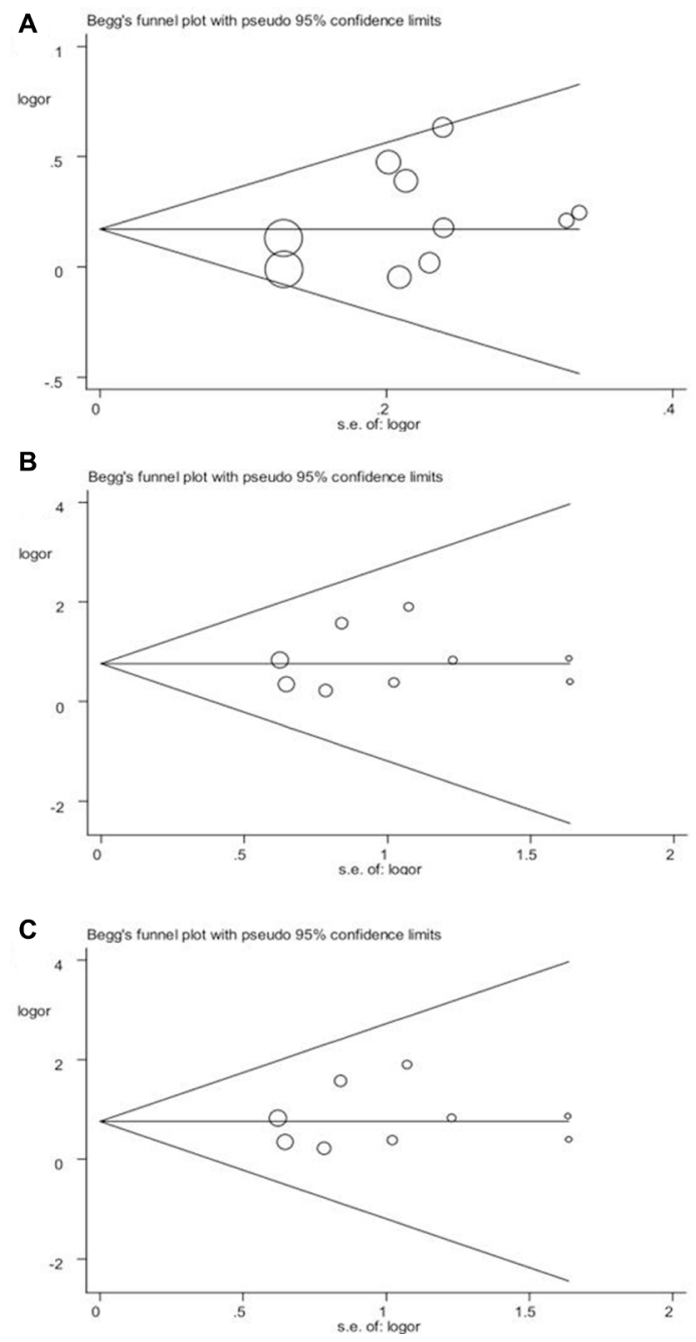

Figure 4: Begg's funnel plot of publication bias in the meta-analysis of the association of CYP2J2 G-50T polymorphism and CAD risk under three genetic models. (A) T vs. G; (B) TT vs. GG; (C) TT vs.GG/GT. Each point represents a separate study for the indicated association. 


\begin{tabular}{lc}
\hline Criteria & Score \\
\hline Representativeness of cases & 2 \\
selected from case population with clearly defined sampling frame & 1 \\
selected from case population without clearly defined sampling frame or with extensive inclusion/exclusion & 0 \\
criteria & \\
No method of selection described & 3 \\
Credibility of controls & 2 \\
Population-based & 1 \\
Blood donors or volunteers & 0 \\
Hospital-based & 2 \\
Not described & 1 \\
Ascertainment of CAD & 0 \\
Clearly described objective criteria for diagnosis of CAD, histological confirmation & \\
Diagnosis of CAD by patient self-report or by patient history & 1 \\
Not described & 0 \\
Genotyping examination & \\
Genotyping done under blinded condition & \\
Not mentioned & 2 \\
Hardy-Weinberg equilibrium & 1 \\
Equilibrium in controls & 0 \\
Disequilibrium in controls & \\
No checked & 2 \\
Association assessment & \\
Assess association between genotypes and CAD with appropriated statistics and adjustment for confounders & 2 \\
Assess association between genotypes and CAD with appropriated statistics without adjustment for & 1 \\
confounders & \\
\hline Inappropriate statistics used & \\
\hline
\end{tabular}

\section{Inclusion criteria}

Studies included in this meta-analysis had to meet the following criteria: (a) case control studies of the association of the CYP2J2 G-50T polymorphism with CAD risk; (b) subjects in the case group had confirmed diagnoses; (c) genotype frequencies for both cases and controls were available; and (d) the distribution of genotypes in the control group was consistent with HWE. If there were numerous articles from the same study, we selected the most relevant one in our analysis. Case reports and reviews were excluded.

\section{Data extraction}

Information was independently extracted by two authors and disagreement was addressed by discussion between them. From each included study, we extracted the following information: the author's first name, publication year, country, ethnicity of the study population, source of controls, genotyping methods, sample size of cases and controls, genotype distribution of the CYP2J2 G-50T polymorphism in cases and controls, and HWE of the control group. Quality of studies was assessed according to the predefined criteria based on previous observational studies (Table 4) [23, 24].

\section{Statistical analysis}

We assessed the strength of association of CYP2J2 G-50T polymorphism with CAD risk with odds ratios (ORs) and 95\% confidence intervals (CIs) in the allele model ( $\mathrm{T}$ vs. G), heterozygote model (GT vs. GG), homozygote model (TT vs. GG), recessive model (TT vs. GG + GT) and dominant model (TT + GT vs. GG). The significance of combined ORs was determined by using the $Z$-test. The $Q$ test was used to evaluate the heterogeneity between the included studies. If $P>0.05$, which indicated no significant heterogeneity, we chose the fixed-effects model (Mantel-Haenszel) to combine the data; if not, the random-effects model (DerSimonianLaird) was applied. Subgroup analyses were performed 
according to ethnicity. We detected publication bias by using Begg's funnel plots and Egger's test. The stability of results was assessed by a sensitivity analysis performed by sequential omission of individual studies. The $\chi 2$-test was used to check the HWE of genotype distribution in the control group. All the tests were two-sided and $P<0.05$ was considered statistically significant. The data analyses were performed using STATA v12.0 software (Stata Corporation, College Station, TX, USA).

\section{Author contributions}

Conceived and designed the experiments: G.X.G., C.J. Performed the experiments: F.G.D, L.J.L., F.J. Analyzed the data: Y.X., D.J., F.G.D Contributed reagents/ materials/analysis tools: W.D.F., C.J., C.L.Y Wrote the paper: C.J., D.J.,G.X.G.

\section{CONFLICTS OF INTEREST}

The authors declare no conflicts of interest.

\section{GRANT SUPPORT}

This study was supported by grants from National Natural Science Foundation of China (81470370).

\section{REFERENCES}

1. Lopez AD, Mathers CD, Ezzati M, Jamison DT, Murray CJ. Global and regional burden of disease and risk factors, 2001: systematic analysis of population health data. Lancet. 2006; 367:1747-1757.

2. Sun J, Qian Y, Jiang Y, Chen J, Dai J, Jin G, Wang J, Hu Z, Liu S, Shen C, Shen H. Association of KCTD10, MVK, and MMAB polymorphisms with dyslipidemia and coronary heart disease in Han Chinese population. Lipids Health Dis. 2016; 15:171.

3. Wung SF, Hickey KT, Taylor JY, Gallek MJ. Cardiovascular genomics. J Nurs Scholarsh. 2013; 45:60-68.

4. Nikpay M, Goel A, Won HH, Hall LM, Willenborg C, Kanoni S, Saleheen D, Kyriakou T, Nelson CP, Hopewell JC, Webb TR, Zeng L, Dehghan A, et al. A comprehensive 1,000 Genomes-based genome-wide association meta-analysis of coronary artery disease. Nat Genet. 2015; 47:1121-1130.

5. Cho EY, Jang Y, Shin ES, Jang HY, Yoo YK, Kim S, Jang JH, Lee JY, Yun MH, Park MY, Chae JS, Lim JW, Shin DJ, et al. Genome-wide association analysis and replication of coronary artery disease in South Korea suggests a causal variant common to diverse populations. Heart Asia. 2010; 2:104-108.

6. Wu S, Moomaw CR, Tomer KB, Falck JR, Zeldin DC. Molecular cloning and expression of CYP2J2, a human cytochrome P450 arachidonic acid epoxygenase highly expressed in heart. J Biol Chem. 1996; 271:3460-3468.

7. Zeldin DC. Epoxygenase pathways of arachidonic acid metabolism. J Biol Chem. 2001; 276:36059-36062.

8. Node K, Ruan XL, Dai J, Yang SX, Graham L, Zeldin DC, Liao JK. Activation of Galpha s mediates induction of tissue-type plasminogen activator gene transcription by epoxyeicosatrienoic acids. J Biol Chem. 2001; 276: 15983-15989.

9. Campbell WB, Gebremedhin D, Pratt PF, Harder DR. Identification of epoxyeicosatrienoic acids as endotheliumderived hyperpolarizing factors. Circ Res. 1996; 78:415-423.

10. Spiecker M, Darius H, Hankeln T, Soufi M, Sattler AM, Schaefer JR, Node K, Borgel J, Mugge A, Lindpaintner K, Huesing A, Maisch B, Zeldin DC, et al. Risk of coronary artery disease associated with polymorphism of the cytochrome P450 epoxygenase CYP2J2. Circulation. 2004; 110:2132-2136.

11. Liu PY, Li YH, Chao TH, Wu HL, Lin LJ, Tsai LM, Chen JH. Synergistic effect of cytochrome P450 epoxygenase CYP2J2*7 polymorphism with smoking on the onset of premature myocardial infarction. Atherosclerosis. 2007; 195:199-206.

12. Zhu Q, Fu Z, Ma Y, Yang H, Huang D, Xie X, Liu F, Zheng Y, Cha E. A novel polymorphism of the CYP2J2 gene is associated with coronary artery disease in Uygur population in China. Clin Biochem. 2013; 46:1047-1054.

13. Xu Y, Ding H, Peng J, Cui G, Liu L, Cianflone K, Wang DW. Association between polymorphisms of CYP2J2 and EPHX2 genes and risk of coronary artery disease. Pharmacogenet Genomics. 2011; 21:489-494.

14. Tzveova R, Naydenova G, Yaneva T, Dimitrov G, Vandeva S, Matrozova Y, Pendicheva-Duhlenska D, Popov I, Beltheva O, Naydenov C, Tarnovska-Kadreva R, Nachev G, Mitev V, et al. Gender-Specific Effect of CYP2C8*3 on the Risk of Essential Hypertension in Bulgarian Patients. Biochem Genet. 2015; 53:319-333.

15. Lung A, Yu L, Chi J, Chun L, Chi T. G-50T Polymorphism of the cytochrome P450 epoxygenase CYP2J2 gene is not associated with the risk of coronary artery disease among Chinese in Taiwan. Acta Cardiol Sin. 2006; 22:148-153.

16. Lee CR, North KE, Bray MS, Couper DJ, Heiss G, Zeldin DC. CYP2J2 and CYP2C8 polymorphisms and coronary heart disease risk: the Atherosclerosis Risk in Communities (ARIC) study. Pharmacogenet Genomics. 2007; 17:349-358.

17. Hoffmann MM, Bugert $P$, Seelhorst U, Wellnitz B, Winkelmann BR, Boehm BO, Marz W. The $-50 \mathrm{G}>\mathrm{T}$ polymorphism in the promoter of the CYP2J2 gene in coronary heart disease: the Ludwigshafen Risk and Cardiovascular Health study. Clin Chem. 2007; 53:539-540.

18. Fava C, Montagnana M, Almgren P, Hedblad B, Engstrom G, Berglund G, Minuz P, Melander O. The common functional polymorphism $-50 \mathrm{G}>\mathrm{T}$ of the 
CYP2J2 gene is not associated with ischemic coronary and cerebrovascular events in an urban-based sample of Swedes. J Hypertens. 2010; 28:294-299.

19. Arun Kumar AS, Kumar SS, Umamaheswaran G, Kesavan R, Balachandar J, Adithan C. Association of CYP2C8, CYP2C9 and CYP2J2 gene polymorphisms with myocardial infarction in South Indian population. Pharmacol Rep. 2015; 67:97-101.

20. King LM, Ma J, Srettabunjong S, Graves J, Bradbury JA, Li L, Spiecker M, Liao JK, Mohrenweiser H, Zeldin DC. Cloning of CYP2J2 gene and identification of functional polymorphisms. Mol Pharmacol. 2002; 61:840-852.

21. Yang B, Graham L, Dikalov S, Mason RP, Falck JR, Liao JK, Zeldin DC. Overexpression of cytochrome P450 CYP2J2 protects against hypoxia-reoxygenation injury in cultured bovine aortic endothelial cells. Mol Pharmacol. 2001; 60:310-320.

22. Xu M, Ju W, Hao H, Wang G, Li P. Cytochrome P450 2J2: distribution, function, regulation, genetic polymorphisms and clinical significance. Drug Metab Rev. 2013; 45:311-352.

23. Camargo MC, Mera R, Correa P, Peek RM Jr, Fontham ET, Goodman KJ, Piazuelo MB, Sicinschi L, Zabaleta J, Schneider BG. Interleukin-1beta and interleukin-1 receptor antagonist gene polymorphisms and gastric cancer: a meta-analysis. Cancer Epidemiol Biomarkers Prev. 2006; 15:1674-1687.

24. Thakkinstian A, D'Este C, Eisman J, Nguyen T, Attia J. Meta-analysis of molecular association studies: vitamin D receptor gene polymorphisms and BMD as a case study. J Bone Miner Res. 2004; 19:419-428. 